\title{
5G Mobile Communication Technology
}

\author{
Huajun Chen ${ }^{1, a}$ and Lina Yuan ${ }^{2, b}$ \\ ${ }^{1,2}$ School of Information Engineering, Tongren University, Guizhou 554300, China. \\ a390832683@qq.com, b893422817@qq.com
}

Keywords: 5G,the user experience rate,spectrum efficiency and energy efficiency,innovation.

\begin{abstract}
The fifth generation $(5 \mathrm{G})$ mobile broadband system will be able to achieve to increase the rate of flow up to 1000 times, enhance the number of connected devices about 100 times and the peak rate of 10 GBPS, guarantee the user experience rate about 10-100 Mbps,smaller time delay and higher reliability,and obviously improve spectrum efficiency and energy efficiency.This paper firstly introduces the evolution of $1 \mathrm{G}$ to $4 \mathrm{G}$, and then explains the evolution, integration and innovation of $5 \mathrm{G}$.
\end{abstract}

\section{Introduction}

With the acceleration of human social informatization, the whole society to the demand level of information and communication has been improved significantly, so to speak, information communication to the value and contribution of human society will be far more than communication itself, and information and communication will be information arteries to maintain the whole social ecological system for normal operation.For its universality of use and convenience of access, wireless mobile communication will no longer be confined to the communication between people, and play more and more important role in information communication systems of the future. People to the demand of all aspects of wireless mobile communication appear explosive growth, which will bring new challenges for the next generation wireless mobile communication system in frequency, technology and operation,etc. The development of future mobile communication has became the research hot spot in trade union.

\section{From 1G to $4 G$}

The first generation mobile communication $(1 \mathrm{G})[1-3]$ is an analog cellular mobile communication network, from the mid-1970s to mid -1980s, and mainly adopts the technology of simulation and frequency division multiple access(FDMA).Due to the limitation of transmission bandwidth, $1 \mathrm{G}$ cannot undertake long-distance roaming of mobile communication, but only a regional mobile communication system. In order to solve the fundamental technical shortcomings existing in the analog system, digital mobile communication technology arises at the historic moment, which is the second generation( $2 \mathrm{G})$ mobile communication systems represented by the GSM and the IS-95, at the beginning of the mid-1980s. 2G takes the technology of digital voice transmission as the core, whose development is to commonly use a mobile phone network standard around the world and lets the user travel across the world with a mobile phone.Europe firstly introduced the system of the pan-European digital mobile communication network (GSM), which is mainly composed of mobile station (MS), the network subsystem (NSS), base station subsystem (BSS) and operations support subsystem (OSS), as shown in Fig. 1.

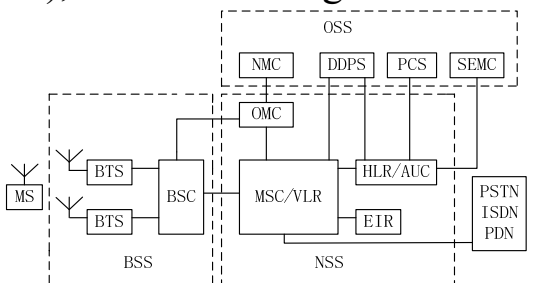

Fig. 1 The structure of GSM system Fig. 2 The structure of IS-95 system

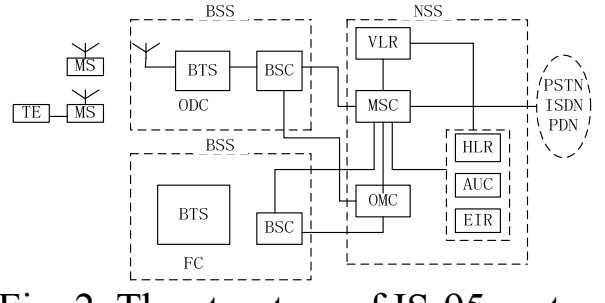


IS-95 system, by America Qualcomm company, is a wireless communication system of code division multiple access (CDMA), whose composition is similar to GSM system, mainly includes the network switching subsystem (NSS), base station subsystem (BSS) and mobile station (MS), as shown in figure 2. $2 \mathrm{G}$ is for the purpose of transmitting voice and low speed data service, therefore also called narrow band digital communication system. General Packet Radio Service(GPRS) is an significant step from GSM to the third generation $(3 \mathrm{G})$ mobile communication system, also called $2.5 \mathrm{G}$.

The third generation (3G) Mobile communication technology is put forward by the International Telecommunication Union (ITU) as early as 1985, then called the Future Public Land Mobile Communication System (FPLMTS), in 1996 changed its name to IMT-2000(International Mobile Telecommunication System-2000), meaning that the System works in the $2000 \mathrm{MHZ}$ band and its top business rate of Kbps.3G is a further evolution on the basis of $2 \mathrm{G}$, which takes broadband CDMA technology as the principal thing and is a mobile communication system that can provide voice and data service. One of its outstanding characteristics is: to achieve individual end users in the future mobile communication that can be high quality to complete mobile communication and transmission among any information at any time and any place with anyone in any way in the global range. The primary difference between $3 \mathrm{G}$ and the first two generations is the promotion of transmitting voice and the speed of data, which can better realize seamless roaming on a global scale, process the images, music, video and other media forms, provide web browsing, telephone meetings, e-commerce, and other information services, and at the same time also consider good compatibility with $2 \mathrm{G}$. The standards of $3 \mathrm{G}$ is mainly WCDMA, CDMA2000,TD-SCDMA and Wimax. The structure of CDMA2000 system, the development and evolution process of CDMA2000 technology, the network structure of WCDMA system and the composition module of TD-SCDMA system, are respectively as shown in Fig. 3, Fig. 4, Fig. 5 and Fig. 6.

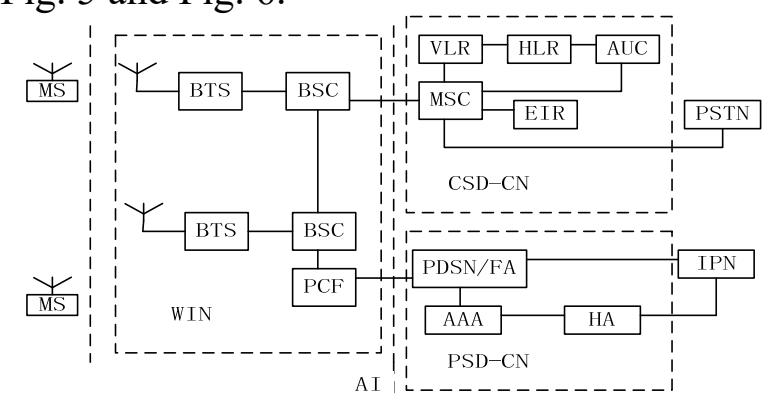

Fig. 3 The structure of CDMA2000 system

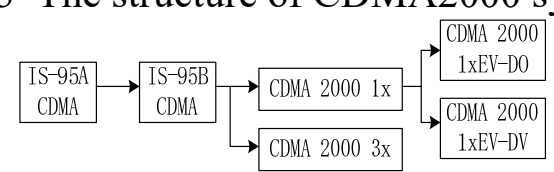

Fig. 4 The development and evolution process of CDMA2000 technology
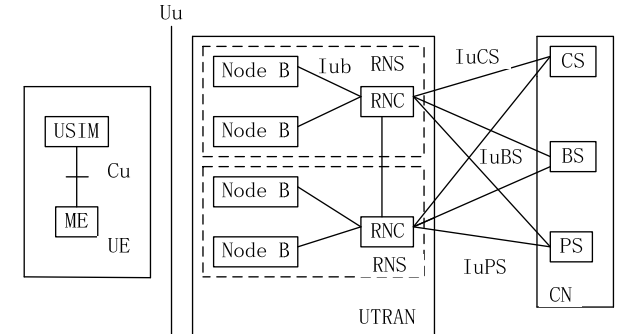

Fig. 5 The network structure of WCDMA system

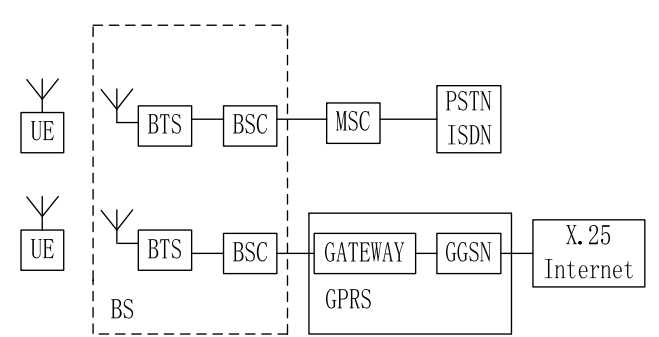

Fig. 6 The composition module of

TD-SCDMA system

The limitations of $3 \mathrm{G}$ are mainly manifested in these aspects:Firstly, be lack of global uniform standard; Secondly, voice exchange architecture as applied to the $3 \mathrm{G}$ is still took their cue from circuit switching of $2 \mathrm{G}$, rather than completely IP form; Thirdly, because of using CDMA technology, be hard to achieve a high rate of communication, not meet the needs of the user to adjust the multimedia business; Fourthly, because the air interface standards of $3 \mathrm{G}$ are limited to core network, 
$3 \mathrm{G}$ is difficult to provide various rate of the business with multiple Qos and performance; Fifthly, due to $3 \mathrm{G}$ adopted different frequencies of different business environment, need mobile terminals to equip with corresponding different hardware and software simulation, while $3 \mathrm{G}$ mobile terminal is not able to realize the different configuration of the multi-service environment, and also cannot achieve the seamless roaming among different frequencies of different business environment.All these limitations push the people for the research and expectation of next generation communication system-4G.

$4 \mathrm{G}$ can be referred to as broadband access and distribution network, with the ability of transmitting asymmetric and more than $2 \mathrm{Mbps}$ data, which can provide $150 \mathrm{Mbps}$ imaging services with high quality for mobile users at full speed, and will be the first to realize three-dimensional images of high quality transmission.It includes fixed broadband wireless access, broadband wireless LAN, mobile broadband systems and interactive broadcast network (based on the ground and satellite system).4G integrates different modes of wireless communication, and mobile users can freely roam from one standard to another standard. The standards of $4 \mathrm{G}$ have more function than $3 \mathrm{G} .4 \mathrm{G}$ can provide wireless service in the network for the different fixed, wireless platforms and across different frequency bands, can be anywhere with a broadband Internet access (including satellite communication and peace flow guide communication), and can provide positioning and timing, data acquisition, remote control and other comprehensive functions.In addition, $4 \mathrm{G}$ is integrated multi-function broadband mobile communication, and is a broadband access IP system. 4G system will meet the challenges of both technology and market in the actual application.From a technical point of view to analyze, $4 \mathrm{G}$, to achieve high data rate, high mobility and seamless roaming, must upgrade the existing mobile communication infrastructure. At first, need to solve these problems of technologies: positioning technology, switching technology, software radio technology,smart antenna technology, wireless transmission technology in the optical fiber, the network protocol and security, transmission technology and modulation and signal transmission technology.

\section{5G}

Mobile communications has experienced from the first generation (1G) mobile communication system to the fourth generation $(4 \mathrm{G})$ mobile communications system, the development of generations of mobile communication system has its typical business ability and signature technology.But in recent years, with the rapid development of integrated circuit technology, the communication system and terminal capacity have greatly ascended, communication technology and computer technology have deeply integrated, and all kinds of wireless access technologies are gradually mature and scale applications.Predictably, the fifth generation(5G)[4] mobile communication technology, can no longer defined as using a business or a typical technical feature to define. 5G mobile broadband system will be demand by human information society of wireless mobile communication system after 2020, which is an integrated multi-services and multi-technologies network, through the evolution and innovation of technology, to meet the future rapid development needs including the extensive data and the connection of various services, and enhance the user experience.

\subsection{The Vision of $5 G$.}

The vision dimensions of 5G mainly describe from three aspects: firstly, social responsibilities and functions, $5 \mathrm{G}$ is human society ecological wireless information system, reflected in: $5 \mathrm{G}$ is connected to the world of wireless channel; Mobile terminals will become the information center of people's life; Mobile communication will become the basic human rights. Secondly, end users, to improve the user experience and follow one's inclinations to enjoy the new life, reflected in: enough, handy and easy to use, cheap, safe and reliable, and individual. Thirdly, the application and operation, the ability of extensive business support and sustained profitability, embodied in: more business ability and better profitability;Enough bandwidth and capacity;Low cost and easy to deploy;Compatible with the existed network and protect the existed investment. 


\subsection{The Key Ability Requirements of 5G.}

According to the analysis of social responsibility and function, end users, business applications and network operations, etc for the vision of future $5 \mathrm{G}$, from the perspective of technical to summarize the key ability requirements of $5 \mathrm{G}$ are as follows:First,increase the rate of flow up to 1000 times and significantly promote throughput per unit area; Second, enhance the number of connected devices about 100 times; Third, reach the peak rate of 10 GBPS; Fourth, guarantee the user experience rate about 10-100 Mbps; Fifth, smaller time delay and higher reliability; Sixth,higher spectrum efficiency; Seventh, obviously improve energy efficiency.

\subsection{The Challenges and Development Trends of 5G.}

Based on the present status of the network, terminal, frequency, and business, to meet the demand of the vision of $5 \mathrm{G}$ wireless mobile communication system has brought the huge challenges in terms of frequency, technology and operation etc.First, the challenge of frequency, mainly including allocated enough spectrum to support business development, flexibly use frequency and adjust radio rules; Second, technical challenges, mainly including the challenge of the integration of system and technology, the challenge of promotion of capacity and spectrum efficiency, the challenge of agility of the Internet of things and business, the challenge of network energy consumption and cost reduction, terminal challenges, and the challenge of the idea of industry ecology for the network architecture and control; Third, the operational challenges, mainly including the challenges of profit modes, operation modes and control rights.

Fully satisfy the demand of information society to the wireless mobile communication system after 2020, and face the challenges of frequency allocation and frequency using in frequency; Face to further enhance lip efficiency, improve coverage efficiency and business ability, reduce energy consumption, reduce the network construction and operation cost, improve the ability of the terminal and reduce power consumption and so on various aspects in technology; Seek new profit model and operation mode, support industrial ecology change given priority to business applications, and realize the rapid and healthy development of industry and operators with consistent profitability in operation.

\section{Conclusion}

5G mobile broadband system will be demand by human information society of wireless mobile communication system after 2020, which is an integrated multi-services and multi-technologies network, through the evolution and innovation of technology, to meet the future rapid development needs including the extensive data and the connection of various services, and enhance the user experience. Evolution, fusion and innovation will be three technical routes geared to the development of 5G. Evolution can give priority to LTE/LTE - an existed technology and frequency of well and flexibly using, and to seek new frequencies and new methods of using frequencies;Fusion can be the comprehensive utilization of the existed wireless mobile communication system, with the lowest price to provide users with the best experience; Innovation can further improve the system efficiency, reduce the cost of equipment and network operations, and meet the needs of the long-term development of the future.

\section{Acknowledgments}

This work was supported by the Collaborative Fund Project of Science and Technology Agency in Guizhou Province Marked by the word LH on 7487[2014], and the reform project of teaching contents and curriculum system in colleges and universities of Guizhou Province on 2014SJJGXM003, and the project of education and cooperation for talent team word in Guizhou in 2015(NO:[2015]67) and partly supported by the National Natural Science Foundation of China(NO.61562703). 


\section{References}

[1]. http://www.elecfans.com/application/Communication/335992.html.

[2]. http://www.gezila.com/news/9903.html.

[3]. http://www.mwrf.net/down/whitepaper/2014/1678.html. 